\title{
Isolated Scrotal Granular Parakeratosis: An Atypical Clinical Presentation
}

\author{
Payal M. Patel, MD; Anastasia O. Kurta, DO; Angela M. Sutton, DO; M. Yadira Hurley, MD;
} A. Mary Guo, MD

\section{PRACTICE POINTS}

- Granular parakeratosis can occur in response to triggers such as irritants, friction, hyperhidrosis, and heat.

- Granular parakeratosis can have an atypical presentation; therefore, a high index of suspicion and punch biopsy are vital to arrive at the correct diagnosis.

- Classic histopathology demonstrates retained nuclei and keratohyalin granules within the stratum corneum beneath which there is a retained stratum granulosum.

To the Editor:

Granular parakeratosis is a rare condition with an unclear etiology that results from a myriad of factors, including exposure to irritants, friction, moisture, and heat. The diagnosis is made based on a distinct histologic reaction pattern that may be protective against the triggers. We present a case of isolated scrotal granular parakeratosis in a patient with compensatory hyperhidrosis after endoscopic thoracic sympathectomy.

A 52-year-old man presented with a 5-year history of a recurrent rash affecting the scrotum. He experienced monthly flares that were exacerbated by inguinal hyperhidrosis. His symptoms included a burning sensation and pruritus followed by superficial desquamation, with gradual yet temporary improvement. His medical history was remarkable for primary axillary and palmoplantar hyperhidrosis, with compensatory inguinal hyperhidrosis after endoscopic thoracic sympathectomy 8 years prior to presentation.

Physical examination revealed a well-demarcated, scaly, erythematous plaque affecting the scrotal skin with sparing of the median raphe, penis, and inguinal folds (Figure 1). There were no other lesions noted in the axillary region or other skin folds.

Prior treatments prescribed by other providers included topical pimecrolimus, antifungal creams, topical corticosteroids, zinc oxide ointment, and daily application of an over-the-counter medicated powder with no resolution.

A punch biopsy performed at the current presentation showed psoriasiform hyperplasia of the epidermis with only a focally diminished granular layer. There was overlying thick parakeratosis and retention of keratohyalin granules (Figure 2). Grocott-Gomori methenaminesilver staining was negative for fungal elements in the sections examined. Clinical history, morphology of the eruption, and histologic features were consistent with granular parakeratosis.

Since the first reported incident of granular parakeratosis of the axilla in 1991, ${ }^{1}$ granular parakeratosis has been reported in other intertriginous areas, including the inframammary folds, inguinal folds, genitalia, perianal skin, and beneath the abdominal pannus. ${ }^{2}$ One case study in 1998 reported a patient with isolated involvement of the inguinal region ${ }^{3}$; however, this presentation is rare. ${ }^{4}$

From the Department of Dermatology, Saint Louis University School of Medicine, Missouri.

The authors report no conflict of interest

Correspondence: A. Mary Guo, MD, SLUCare Academic Pavilion, 3rd Floor, Dermatology, 1008 Spring Ave, St. Louis, MO 63110 (amary.guo@health.slu.edu).

doi:10.12788/cutis.0327 


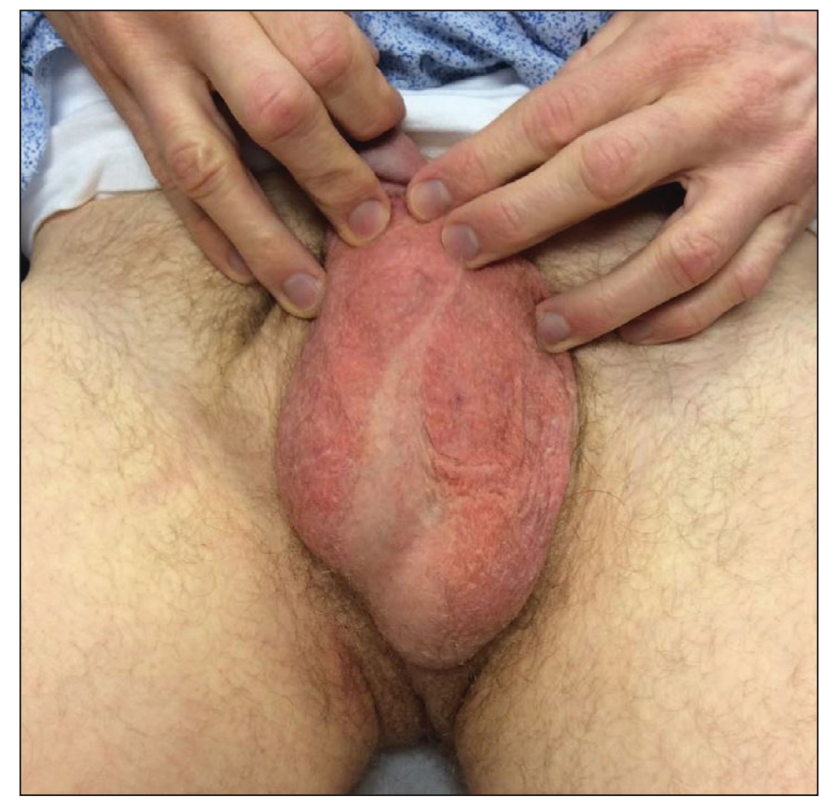

FIGURE 1. Well-demarcated, scaly, erythematous plaque affecting the scrotal skin and sparing the median raphe, penis, and inguinal folds in a 52-year-old man.

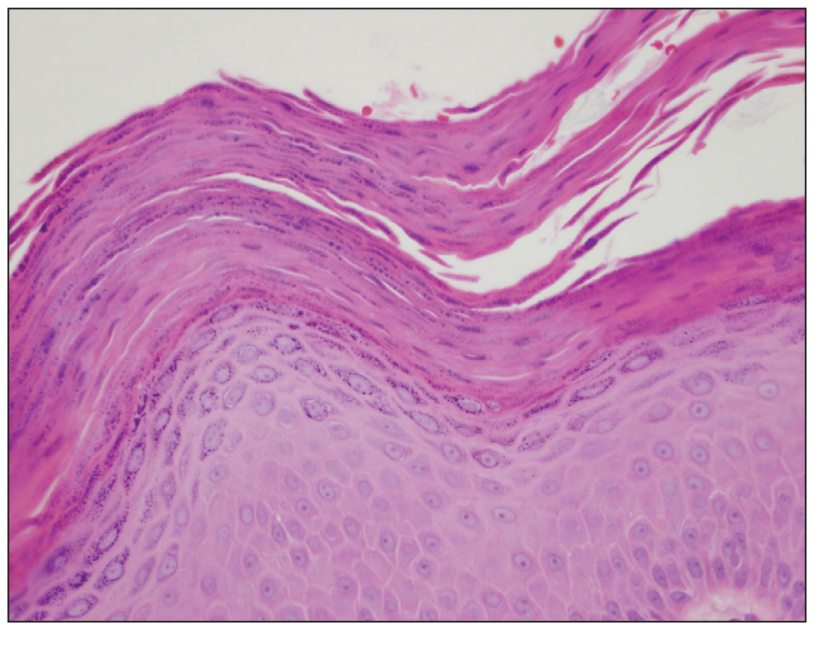

FIGURE 2. A punch biopsy showed psoriasiform hyperplasia of the epidermis with a thick parakeratotic layer and retention of keratohyalin granules (H\&E, original magnification $\times 400)$.

This condition has been reported in both sexes and all age groups, including children. ${ }^{5}$

Granular parakeratosis classically presents as erythematous to brown hyperkeratotic papules that coalesce into plaques. ${ }^{6}$ It is thought to be a reactive inflammatory condition secondary to aggravating factors such as exposure to heat, ${ }^{7}$ moisture, and friction; skin occlusion; repeated washing; irritation from external agents; antiperspirants; and use of depilatory creams. ${ }^{8}$ Histopathology is characteristic and consists of retained nuclei and keratohyalin granules within the stratum corneum, beneath which there is a retained stratum granulosum. Epidermal changes may be varied and include atrophy or hyperplasia.

Murine models have postulated that granular parakeratosis may result from a deficiency in caspase 14, a protease vital to the formation of a well-functioning skin barrier. ${ }^{9}$ A cornified envelope often is noted in granular parakeratotic cells with no defects in desmosomes and cell membranes, suggesting that the pathogenesis lies within processing of profilaggrin to filaggrin, resulting in a failure to degrade keratohyalin granules and aggregation of keratin filaments. ${ }^{10}$ Granular parakeratosis is not known to be associated with other medical conditions, but it has been observed in patients receiving chemotherapy for breast ${ }^{11}$ and ovarian ${ }^{12}$ carcinomas. In infants with atopic dermatitis, granular parakeratosis was reported in 5 out of 7 cases. ${ }^{6}$ In our patient with secondary inguinal hyperhidrosis after thoracic sympathectomy, granular parakeratosis may be reactive to excess sweating and friction in the scrotal area.

Granular parakeratosis follows a waxing and waning pattern that may spontaneously resolve without any treatment; it also can follow a protracted course, as in a case with associated facial papules that persisted for 20 years ${ }^{13}$ Topical corticosteroids alone or in combination with topical antifungal agents have been used for the treatment of granular parakeratosis with the goal of accelerating resolution. ${ }^{2,14}$ However, the efficacy of these therapeutic interventions is limited, and no controlled trials are underway. Topical vitamin D analogues ${ }^{15,16}$ and topical retinoids ${ }^{17}$ also have been reported with successful outcomes. Spontaneous resolution also has been observed in 2 different cases after previously being unresponsive to topical treatment. ${ }^{18,19}$ Treatment with Clostridium botulinum toxin A resulted in complete remission of the disease observed at 6-month follow-up. The pharmacologic action of the neurotoxin disrupts the stimulation of eccrine sweat glands, resulting in decreased sweating, a known exacerbating factor of granular parakeratosis. ${ }^{20}$

In summary, our case represents a unique clinical presentation of granular parakeratosis with classic histopathologic features. A high index of suspicion and a biopsy are vital to arriving at the correct diagnosis.

\section{REFERENCES}

1. Northcutt AD, Nelson DM, Tschen JA. Axillary granular parakeratosis. J Am Acad Dermatol. 1991;24:541-544.

2. Burford C. Granular parakeratosis of multiple intertriginous areas. Australas J Dermatol. 2008;49:35-38.

3. Mehregan DA, Thomas JE, Mehregan DR. Intertriginous granular parakeratosis. J Am Acad Dermatol. 1998;39:495-496.

4. Leclerc-Mercier S, Prost-Squarcioni C, Hamel-Teillac D, et al. A case of congenital granular parakeratosis. Am J Dermatopathol. 2011;33:531-533.

5. Scheinfeld NS, Mones J. Granular parakeratosis: pathologic and clinical correlation of 18 cases of granular parakeratosis. J Am Acad Dermatol. 2005;52:863-867.

6. Akkaya AD, Oram Y, Aydin O. Infantile granular parakeratosis: cytologic examination of superficial scrapings as an aid to diagnosis. Pediatr Dermatol. 2015;32:392-396. 
7. Rodríguez G. Axillary granular parakeratosis [in Spanish]. Biomedica. 2002;22:519-523.

8. Samrao A, Reis M, Niedt G, et al. Granular parakeratosis: response to calcipotriene and brief review of current therapeutic options. Skinmed. 2010;8:357-359.

9. Hoste E, Denecker G, Gilbert B, et al. Caspase-14-deficient mice are more prone to the development of parakeratosis. J Invest Dermatol. 2013;133:742-750

10. Metze D, Rutten A. Granular parakeratosis-a unique acquired disorder of keratinization. J Cutan Pathol. 1999;26:339-352.

11. Wallace CA, Pichardo RO, Yosipovitch G, et al. Granular parakeratosis: a case report and literature review. J Cutan Pathol. 2003;30:332-335.

12. Jaconelli L, Doebelin B, Kanitakis J, et al. Granular parakeratosis in a patient treated with liposomal doxorubicin for ovarian carcinoma. J Am Acad Dermatol. 2008;58(5 suppl 1):S84-S87.

13. Reddy IS, Swarnalata G, Mody T. Intertriginous granular parakeratosis persisting for 20 years. Indian J Dermatol Venereol Leprol. 2008;74:405-407.
14. Dearden C, al-Nakib W, Andries K, et al. Drug resistant rhinoviruses from the nose of experimentally treated volunteers. Arch Virol. 1989;109:71-81.

15. Patel U, Patel T, Skinner RB Jr. Resolution of granular parakeratosis with topical calcitriol. Arch Dermatol. 2011;147:997-998.

16. Contreras ME, Gottfried LC, Bang RH, et al. Axillary intertriginous granular parakeratosis responsive to topical calcipotriene and ammonium lactate. Int J Dermatol. 2003;42:382-383.

17. Brown SK, Heilman ER. Granular parakeratosis: resolution with topical tretinoin. J Am Acad Dermatol. 2002;47(5 suppl):S279-S280.

18. Compton AK, Jackson JM. Isotretinoin as a treatment for axillary granular parakeratosis. Cutis. 2007;80:55-56.

19. Webster CG, Resnik KS, Webster GF. Axillary granular parakeratosis: response to isotretinoin. J Am Acad Dermatol. 1997; 37:789-790.

20. Ravitskiy L, Heymann WR. Botulinum toxin-induced resolution of axillary granular parakeratosis. Skinmed. 2005;4:118-120. 